\title{
Da Autonomia Municipal
}

(Reflexões sôbre o regime das cartas próprias)

\section{Aderson Dutra}

A autonomia local brasileira, escreve OSCAR Tenório, nasceu com as capitanias hereditárias. A Constituição Imperial, por seu turno, prossegue c mesmo autor, reconheceu a existência do govêrno municipal, com específicas funções municipais (Repertório Enciclopédico do Direito Brasileiro, Vol. 5, pp. 190-191). Fôrça é convir, todavia, em que se tratava de uma autonomia mais aparente do que real, tantas e tão extensas as faculdades intervencionistas reservadas ao Poder Central.

A primeira Constituição Republicana, como se sabe, também acolheu e proclamou c princípio da autonomia municipal, s s bem que em têrmos vagos e impreciscs, segundo se colhe da formulação do seu art. 68 , em que ficou condensada tôda a matéria, como se vê:

"Os Estados organizar-se-ão de forma que fique assegurada a autonomia dos municípios, em tudo quanto respeite ao seu peculiar interêsse."

De assinalar, porém, que, entre a Constituição do Govêrno Prcvisório (Decreto n. ${ }^{\circ} 510$, de $22 / 6 / 1890$ ) e a Carta de 1891 , ocorreu sensível retrocesso no tocante à conceituação da autonomia municipal, eis que a primeira, como se viu, não deu a medida dessa autonomia, preferindo, com flagrante prejuízo para a configuração do instituto, usar da cláusula do "peculiar interêsse" como elemento definidor das atribuições comunâis, enquanto que o Decreto do Govêrno Provisório, por certo mais bem inspirado, previra expressamente, como traço característico das franquias municipais, a eletividade da administração local.

Foi na Constituição de 1934, todavia, que a matéria encontrou sistematização consentânea com os anseios da coletividade brasileira, pcis que aí a autonomia municipal teve o seu conteúdo definido em têrmos objetivos, sob o triplice aspecto político, financeiro e admiristrativo (art. 13).

Igual critério foi seguido pelo constituinte de 1946, que também se empenhou em fixar com nitidez os justos limites da autonomia municipal, condicionando, porém, o poder de auto-organização dos municípios, àquilo que respeite ao seu peculiar interêsse, cláusula que vem se prestando às mais va- 
riadas especulações, conforme a maior ou mencr latitude que se queira emprestar a essa tão vaga fórmula.

Da Constituição de 1934, desta sorte, cmergiu o município como entidade política, pela expressa concessão, que se lhe fêz, de competência legislativa privativa ao lado da União e dos Estados, assim como pela explícita competência para decretar e arrecadar certos e determinados tributos.

Isto constitui, por certo, uma singularidade do Direito Constitucionai Brasileiro, sabido que, como esclarece o insigne Prof. ViCTOR NUNES LEAL, em bem lançado artigo de doutrina,

A regra geral, nas Constituições federais, é a repartição dual das competências : da Uniấo e dos Estados. Não é habitual a discriminação de uma esfera de competência menor que a dos Estados, ou seja, de uma esfera de competência municipal (Revista Brasileira dos Municípios - Vol. 9 - Áno III - Janeiro-Março de 1950 , p. 67).

Até ao advento da Carta de 1934, pois, sobravam razões ao emérito CASTRO NUNES para afirmar que a autonomia municipal se reduzia "a uma autonomia delegada pelo Estado para a administração de assuntos estritamente locais" (Apud PAUlo Barbosa de CAMpos Filho in Revista Forense, Vol. 129, p. 602 ).

E razões the sobravam, porque, diante da imprecisãc do art. 68 da Constituição de 1891, os Estados eram árbitros das franquias municipais, pois que a êles fôra permitido fixar o sentido e alcance do que se deveria entender por "peculiar interêsse" dos municípios, cumprindo-lhes, conseqüentemente, dar a medida daquilo que se convencionara chamar de "autonomia municipal".

\section{II}

Feito êste breve escôrço histórico do princípio da autonomia municipal no Brasil, passemos ao exame de certo aspecto que, para muitos, constitui um dos traços característicos dessa mesma autonomia, ou seja, a prerrcgativa de os municípios elaborarem as suas próprias Leis Orgânicas, prerrogativa que se traduz no regime das chamadas cartas próprias.

Não há dúvida de que o poder de auto-organização municipal tem sido preconizado e defendido por políticos e publicistas, que vêem nessa prerrogativa uma das peças essenciais da autonomia comunal, sendo digna de nota, a êste respeito, a tentativa feita pelo deputado MEIRA DE VASCONCELOS, na Assembléia Constituinte de 1890 , visando a conferir competência aos municípios para a elaboração de suas próprias Leis Orgânicas, tentame que, como se sabe, foi repelido pela citada Assembléia.

Em favor de uma autonomia municipal ampla e irrestrita, sob a Constituição de 1891, opinou o eminente e saudoso BARBALHO, em seus conhecidos 
e lúcidos Comentários, onde, após apreciar a emenda MeIRA DE VAsconcelos, assentou,

"O pleno exercício da liberdade municipal é não só um direito, mas uma condição sine qua de uma organização constitucional, sôbre a base do self government" (pág. 282).

Não terá sido êsse, aliás, o único ensaio para dotar cs Municípios do poder de autc-organização, sabiāo que, segundo refere LEVI CARNEIRo, também foi recusado, pelo Constituinte de 1934, certo dispositivo do projeto do Itamarati que estabelecia a "carta municipal própria", em certos casos e sob certas condições (Organização dos Municípios e do Distrito Federal - Rio do Janeiro - 1953 - pág. 261). .

Para Paulo Barbosa de CAMpos Filho, eminente Presidente do Instituto dos Advogados de Săo Paulo, que, sôbre o assunto, produziu um estudo meritório, oferecido, como contribuição do Instituto ao Congresso de Direito Constitucional reunido na cidade do Salvador, em comemoração ao centenário de Rui Barbosa, para êsse ilustre jurista o poder de auto-organização é inseparável da autoncmia municipal, a ponto de afirmar que "onde não há cartas orgânicas, vindas dos própi ios municípios, não há, pode-se dizer, autonomia municipal no sentido puro da expressão, senão e apenas organização autárquica, semelhante à que resulta de mera descentralização de serviços" (Revista Forense, Vol. 129, pág. 602). D

Em abcno de sua tese, o ensaísta rememora o ensinamento de BIELSA, que considera fundamental, para que exista autonomia, o dar-se ao município sua própria constituição, ou seja, suas próprias normas jurídicas constitutivas, condição que reconhece faltar ao regime municipal argentino.

O poder de auto-organização, entre nós, tem sido insistentemente reivindicado pelos municípios, tendo sido inscrito na Carta de Declaração de Princípios, Direitos e Reivindicações Municipais, promulgada pelo "I Congresso Nacional dos Municípios Brasileircs", realizado em Petrópolis, no ano de 1950, donde a oportunidade de qualquer estudo que, com maior ou menor profundidade, verse o delicado assunto.

De jure condento, pois, a matéria deve ser cuidadosamente apreciađa, dado tratar-se de assunto da maior relevância para as três esferas de govêrno, mesmo porque, para evitar usurpações que tanto comprometem a harmonia entre os poderes, será de tôda conveniência colocar a questão em têrmos que não ensejem disputas e reivindicações impertinentes.

Dizemos de jure condendo, porque, segundo o direito ccnstituído brasileiro, aos municípios não é lícito reivindicar o poder de auto-organizaçäo, já que lhes falta a necessária base constitucional, sabido que a matéria não está contemplada em nenhum dos itens do art. 28 da Carta Federal, onde apenas se defere às comunas o poder de legislar sôbre a matéria administrativa do seu peculiar interêsse, assim como sôbre a organização dos serviços públicos locais. 
Ao preconizarmos um reexame da matéria, não nos deixamos anımar, diga-se de passagem, do propósito de pugnar pela adoção do regime das cartas próprias. Bem ao revés, entendemos que as leis orgânicas municipais, dispondo apenas sôbre a organização e coordenação dos poderes comuna1s, devem ser elaboradas pelos Estados, tanto mais que, no seu âmbito, não se devem incluir matérias atinentes às peculiaridades locais, o que contraviria o princíp1o da autonomia dos municípios.

Expungida a lei orgânica dos pormenores respeitantes à organizaçao dos serviços locais, nãu vemos por que a mesma não deva ser uma só para tôdas as Comunas, mesmo porque, segundo assinada Oscar TENóRIo :

"O direito público brasileiro tem procurado ncvos rumos, no sentido da denominada racionalização. Abandona-se o critério clássico, dominante no Século XIX, do liberalismo políticc, da autonomia rigorosa dos órgãos locais, em prol da "racionalização" da atividade administrativa do Estado. Daí o interêsse com que se vem procurando estabelecer, quanto ao direito municipal, a unidade na variedade" (ob. cit., pág. 193).

E certo que a Carta Política do Rio Grande do Sul, em seu art. 154, conferiu aos municípios; ou melhor, às Câmaras Municipais, competência para votar e reformar as leis orgânicas, singularidade que nos convida a uma breve digressão sôbre a legitimidade dessa outorga, face à letra e espíritc do Estatuto Supremo, máxime porque, segundo reconhece o abalizado Francisco Machado Vila, em sua prestimosa obra O Município no Regime Constitucional Vigente, Edição Freitas Bastos, 1952, pág. 78, "êsse critério corresponde à tradição constitucional do Rio Grande do Sul, o qual, desde a sua primeira constituição, com interrupção lćgica no período inaugurado em 1937, vem outorgando ao município a prerrogativa de elaborar a sua própria carta, dando, assim, uma compreensão mais larga ao princípio da autcnomia municipal".

Para o autor, dada a ausência de cláusula expressa na Constituição Federal sôbre o assunto, aos Estados é lícito reter ou delegar a competênciáa para elaborar as cartas municipais, donde, a seu ver, a legitimidade do procedimento do constituinte gaúcho, que, fiel à tradição constitucional de seu Estado, optou pela segunda fórmula, deferindo aos municípios o poder de autoorganização, o que redunda na instituição do, regime das chamadas cartas próprias.

Dissentimos, data vênia, do ponto de vista sustentado pelo autcrizado publicista, cujo raciocínio gira em tôrno da ausência de cláusula expressa na Constituição Federal, eis que tal omissão, quando muito, autorizaria o Estado a legislar sôbre a matéria, já que aos Estados se reservam todos os poderes que, implícita ou explicitamente, não thes sejam vedados pela Constituição (Constituição, art. $36, \S 2 \cdot^{\circ}$ ).

Eis por que se nos afigura mais consentânea com a realidade a lição de outro esclarecidc municipalista, o Senhor C. MARTINS DA Silva, autor do livro Direito Público Mưnicipal e Administração dos Municípios, obra que encerra lúcidos comentários à Lei Orgânica dos Municipios de Minas Gerais, onde 
o autor afirma que "a soluçấo dada ao problema municipal pela Constituição Mineira, que reservou à Assembléia Legislativa do Estado competência para regular a organização dos municípios, consulta à letra e ao espírito da Constituição da República, e vai retomar a boa tradição do nosso direito público municiọal, formada desde a instauração do regime republicano" (pág. 51).

Concludente, a êste respeito, é o pronunciamento do preclaro LEVI C $\mathrm{C}_{\mathrm{AK}-}$ NEIRO, o qual, após longas e judiciosas considerações, assim se manifesta, em têrmos que bem convencem da inconstitucicnalidade da delegação conferida pela Constituição do Rio Grande do Sul :

"A Constituição de 1946 não reproduziu os dispositivos citados da Constituição de 1891, que se poderiam considerar colidentes. Perdura, contudo, o princípio característico do nosso regime federativo, que atribui aos Estados (art. $18, \S 10^{\circ}$ ) todos cs poderes remanescentes - aliás, já expresso nc art. $65,2 .^{\circ}$, da Constituição de 1891 - e que basta, a meu ver, para justificar a expediçảo, pelos Estados, das leis or gâanicas dos municípios".

"Além disso, sòmente aos Estados - e não aos municípios dá a Constituição Federal (art. 18), em têrmos expressos, a faculdade de se regerem pela Constituição e pelas leis que adotaram".

"Assim, não só a letra da Constituição exclui a auto-organização dos municípios; também parece contrária ao sistema adotado pela mesma Constituição" (Ob. cit., págs. 258-259).

E mais adiante :

"Inexistente o dispositivo que mandava os Estados organizarem seus municípios, a competência para tal organização se inclui entre os poderes remanescentes que cabem aos Estados - e pareceme que êstes, exercendo tal competência com maior ou menor extensão, com maior ou menor detalhe, não podem omiti-la. Não podem - basta êsse exemplo - desistir da fiscalização financeira dos municípios. Parece-me, pois, inconstitucional a outorga aos municípios do poder de auto-organização" (página 281).

Nem se argumento que o poder de auto-organização seja uma decorrência dos chamados poderes implícitos municipais, poderes que, no sentir do insígne VICTOR NUNES LEAL, prevalecem sôbre os poderes estaduais remanescentes (Estudos sôbre a Constituição Brasileira, Fundação Getúlio Vargas, pág. 138); e não se argumente, porque, data vênia, onde houver poder implícito não pode haver poder remanescente, que, como se sabe, é o que resta dos poderes explícita cu implìcitamente outorgados à União e aos municípios. Se à União ou aos municípics forem reconhecidos certos poderes, faculdades ou prerrogativas, implícita ou explìcitamente, então não será lícito cogitar de poderes remanescentes dos Estados, porque não será possível considerar remanescente aquilo que está vinculado ou integrado na competência de qualquer outra entidade política.

Sabe-se, ademais, que os poderes implícitos pressupõem poderes expressos. a que aderem e de que são consectário lógico, tal como reconhece o festejado publicista Osvaldo Trigueiro, escudado na lição de Evans (Os Poderes 
do Presidente da República, in Estudos sôbre a Constituição Brasileira, págst. 86-87), o que nos levaria a perquirir da existência de poderes municipais de tal monta que, implìcitamente, envolvessem o poder de auto-crganização, o que se não pade constatar.

Não estando, pois, o poder de organização municipal expressamente compreendido na competência da União, da mesma sorte que não se inclui entre as atribuições municipais, nem derivandc, por outro lado, como poder implícito, de qualquer das prerrogativas conferidas a essas duas entidades, fôrça é convir em que se trata de um poder remanescente dos Estados, insuscetível de delegação ou transferência.

Partindo dessa premissa foi que o Supremo Tribunal, acorde com a melhor doutrina, fulminou a pretensão dos municípios paranaenses de elabcrarem as suas próprias cartas, decisão que a Revista de Direito Administrativo divulgou em seu n. ${ }^{\circ} 36$, págs. 239-248, com a seguinte ementa :

"Cabe, a cada Estado, votar a lei orgânica de seus Municípios, podendo estabelecer a gratuidade da função dos vereadcres, ou impor limitações à remuneração dêstes."

Na discussão dêșse autêntico leading case tomaram parte todos os Ministros do Pretório Excelso, cujos votos encerram magníficas lições de Direito Constitucional, merecendo destaque especial, pela veemência dos têrmos em que está vazado, o seguinte excerto do voto proferido pelo Ministro LUIz GalotTi, Relator da matéria :

"Nada autoriza a suposição de que passou a competir a cada município elaborar a sua própria lei crgânica, o que importaria em atribuir aos municípios poder de auto-organização ou poder constituinte, que jamais tiveram e jamais pretenderam. Seria, aliás, uma subversão completa do regime, porque dotadas de autonomia constituinte, as municipalidades seriam republiquetas em cada um dos Estados, êstes seriam federações de municípios, em contrário à noção de que Estado Federal é a União, federados são os Estados, cada um dos quais é do tipo simples e unitátio, ainda que descentralizam os Estados unitários, sob a forma comunal ou municipal".

O Ministro MÁRIo GuIMARÃEs, com o brilho que caracteriza os seus pronunciamentos, estudou a questão particularmente em face dos poderes remanescentes do Estado, assim resumindo o seu pensamento:

"A quem compete organizar os municípios? Não sendo à União, cabe êsse poder ao Estado por fôrça do supracitado artigo (referese ao art. 18, $\S 1 .^{\circ}$, da Const. Federal).

"No poder de organigar esta o de fixar as atribuições e de dizer se as funções dos órgãos que as desempenham hão de ser remuneradas cu não".

Nesta ordem de idéias, forçoso sərá concluir pela inconstitucionalidade do art. 154, item II, da Carta Política do Rio Grande do Sul, que, explicitamente, deferiu às Câmaras Municipais o poder de votar e reformar as leis orgânicas dús municípios. 
Por inconstitucional, igualmente, temos a Lei n. ${ }^{\circ} 163$, de 17 de dezembro de 1954, votada pela Assembléia Legislativa do Amazonas, por via da qual foi atribuído aos municípios o poder de auto-organização, tanto mais que, na Constituição de nosso Estado, êsse poder está expressamente reservado ao órgão legiferante estadual (art. 22, item XVI, letra c), insuscetível, portanto, de delegação ou substabelecimento às municipalidades.

\section{III}

Não queremos encerrar esta palestra sem alertar os espíritos para os males que poderão advir de um exagerado alargamento da autonomia municipal, c que colocaria as comunas fora das vistas e da vigilância das entidades maiores, especialmente do Estado, que, em última análise, responde pela regularidade das finanças municipais, tanto que se the permite intervir nos municípios para thes regularizar essas mesmas finanças, nos casos previstos no art. 23 da Constituição Federal, não sendo lícito pensar-se que apenas the caiba função terapêutica e não profilática.

Não há negar que os municípios, sobretudo cs pequenos e incipientes municípios, carecem de melhores e mais produtivas fontes de receita que thes permitam dar a necessária expansão aos seus serviços. Não advogamos, porém, a concessão de novas vantagens às municipalidades, sem que se cogite, inicialmente, de tornar responsável a administração municipal, pois que é de todos conhecido, salvo honrosas exceções, o estado de abandono em que se encontra a maioria das nossas comunas, dessangradas e espoliadas por administradores sem escrúpulcs, cujas contas a rigor nunca foram tomadas, conhecida que é a inidoneidade técnica e a falta de isenção de ânimo da maioria dos integrantes das Câmaras Municipais, que de nenhum modo fiscalizam a gestão dos chefes comunais.

Todos sabemos das vantagens de ordem financeira que a Constituição de 1946 outorgou aos municípics, inclusive a participação na arrecadação do impôsto de renda, fundo rodeviário, etc. Nada obstante, muitos municípios, do ano de 1946 a esta parte, não poderão exibir umas poucas barracas que possam justificar cu ao menos explicar a aplicação dos milhões de cruzeiros recebidos.

E para que se não pense que o progresso municipal, entre nós, está sendo obstado pelas possíveis restrições impostas à autonomia local, ouçamos a PAUlo BARBosa DE CAMPOS Filho, estrênuo defensor das franquias municipais, o qual, em frase lapidar, assim reconhece a plenitude da autonomia do município brasileiro:

"Em matéria de franquias municipais, atingimos, portanto, quer com a participação dos municípios na discriminação constitucional de rendas, quer com os seguros contornos de que hoje se reveste a sua autonomia, o ponto culminante da nossa evcilução político-administrativa, a justificar amplamente o enunciado desta tese, na parte em que se refere ao fortalecimento da autonomia à luz da Constituição de 1946". 
Atente-se, finalmente, para a advertência formulada pelo Prof. VICTOR Nunes LEAL, municipalista de estirpe, a cujos ensinamentos mais de uma vez nos reportamos, advertência que decorre das condições atuais da vida brasileira e quiçá do mundo. Diz o mestre, em sua preciosa obra Coronelismo; Enxada e Voto:

"Parece fora de dúvida que as condições da vida moderna não são muito favoráveis ao desenvolvimento das atribuições municipais, ou, em outras palavras, são mais favoráveis à extensão dos poderes centrais" (página 64).

Estas, meus Senhores, as reflexões de quem nãc milita nas hostes municipalistas, mas que, tanto quanto os mais sinceros municipalistas, deseja dias melhores para as comunas, e, por via de conseqüência, para o homem do interior, progresso que pode e deve ser alcançado à base de trabalho, de perseverança, sobretudo de honestidade dos dirigentes municipais, cuja inépcia ou má fé jamais poderão ser perdoadas ou sequer atenuadas pela invocação de possíveis limitações à autonomia municipal. 